\section{Informal Report}

uC. $79 p$

Reporting Date: October 1975 Issued: November 1975

\title{
Effects of Neutron Streaming and Geometric Models on Molten Fuel Recriticality Accidents
}

by

Thornas P. McLaughlin

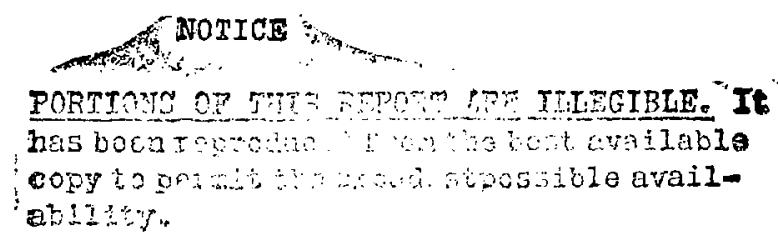

$\div$

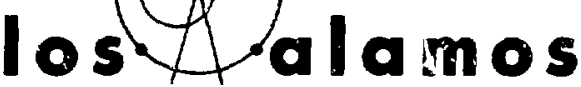

sclentific laboratory

of the University of Californio

LOS ALAMOS, NEW MiXICO 87545

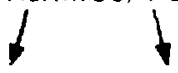

An Aftirmative Action/Equal Opportunity Emplayer 
In the interest of prompt distribution, this report was not edited by the Technical Information staff.

Work supported by the U.S. Energy Research and Development Administration's Division of Reactor Research and Development.

Printed in the United States of America. Available from National Technical Information Service U S Department of Commerce 5285 Port Royal Road Springtield, VA 2215

Price: Prinled Copy $\$ 400$ Microtiche $\$ 2.25$

This report wros nrepared as an acrount of work sponsored bs The linited sitates Government. Neither the United Stales nor thr Inited states Finerzy Hesearch and Itevelopment Administration, nor any of their employesw, nor any of their con-
Irartors, aubrontractors, or their emploveen, maken an. warranty, express or implied, or essumes any Irag l liahilitvo ceaponuibility for the acruracy. completenens, or uhefulmenn of anv information. appuratus. produrt. Or process disclomed, or
reprearnta that ita une would not infringe privately owned rights. 
UNCLASSIFIED

EFFECTS OF NEUTRON STREAMING AND GEOMETRIC MODELS ON MOLTEN FUEL RECRITICALITY ACCIDENTS

by

Inomas P. McLaughlin

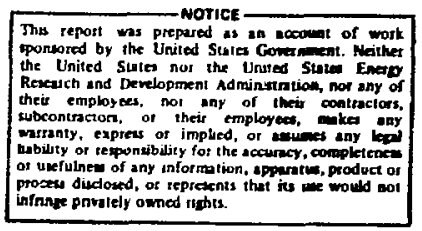

ABSTRAC'T

A postulated fast reactor accident which has been extant for many years is a recriticality following partial or complete core melting. Independently of the cause or probability of such a situation, certain cases can be defined and some facets of the dynamic history of these cases can be described with more than enough accuracy for safety considerations. Calculations were made with the PAD code for systems with 10 vol\% voids and varying reactivity insertion rates. Addisionally, two distinct geometric and equation of state models were investigated in conjunction with a model which accounted for possible neutron streaming reactivity effects. Significant results include fission and kinetic energy, temperatures and pressures.

\section{INTRODUCTION}

This report continues the study of criticality energetics should a mass of fast reactor fuel become molten, reasonably homogeneous, and have imposed upon it reactivity added at a high, constant rate. The situation is further specialized to represent the case of a mildiy bolling 11quid. The neutronics model in the PAD code accounted for possible reactivity changes should bubbles collapse during a rapld power (and liquid temperature) rise; and two hydrodynamics models, treating voids both explicitly and implicitly, were included in the study.

Previous progress reports and publications on this subject have reported energy releases from simflar, postulated recriticality events.1,2,3 All of the prion studies, however, employed an implicit void treatment and did not consider possible reactivity feedback resulting from changes in the neutron mean chord lene:h. A recent progress report analyzed the neutronics and reactivity worth of volds in fissile systems. 4 This reactivity is associated with the streaming of neutrons through randomly distributed bubbles or volds and is commoniy known as the Behrens effect. 5 Th1s report describes $a$ first attempt to combine the reactivity feedback that is possible from the collarse of bubbles with the PAD code, employinf an explicit void treatment. Continuins examInation of some conservatisms and model assumptions may be necessary for a realistic rvaluation of this hypothetical scenarto. Puior transport calculations quantified the Behrens effect for systems characterized by fuel with a $k_{\infty}$ of 1.33 .4 This analyils has been extended to include fuel compositions with $k_{\infty}=1.50$ and $k_{\infty}=2.00$. As before, these results are compared with the theoretical work reported by Nicholson. ${ }^{6}$ A neutronsas model has veen incorporated into the PAD analyses which calculates the 
(regionwise) react1vity reedback associated with changes in the vold content at each ine step. This model also Includes a spaial reactivity weighting function.

The hydrodynamics models were idealized to unreflected spheres of fuel of raiii 29, 44 , and $53 \mathrm{~cm}$, corresponding to fuels with $k_{\infty}=2.0,1.5$, and 1.33 . respectively. An average initial vold content of 10 vol: was employed in all calculations. Parameter variations were performed for: reactivity insertion rate; streaming reactivity feedback (magnitude and spatial weighting function); geometric model (homogeneous and layered); vold s1ze. Significant results include fission and kinetic energy releases as well as reactivities, temperatures, and pressures.

In order that the postulated scenario and underlying models and assumptions be clear, they are: (1) an incident occurs which leads to fuel and clad rielting, (2) a container is afforded either by fuel and clad freezing in the lower reflector regions or by other structures below the core, (3) more fuel melts and is contained In this "bucket"; (4) the retained fuel bolls, elther because of decay heat or from fsssion heating, (5) something (unspecified) causes a severe reactivity ramp and power excursion with a subsequent sharo temperature rise, and (6) the rapid temperature rise causes the liquid fuel to expand and collapse the vapor bubbles. This collapse produces a decrease in the neutron mean chord length and a positive reactivity reedback - in addition to the Impressed ramp.

\section{STREAMING REACTIVITY ANALYSIS}

The magnitude and consequences of reactivity changes accompanying the partial or complete collapse of a distribution of gas or vapor bubbles has been the subject of recent reports. 4,$5 ; 7$ This bubble collapse is postulated to occur as a result of expansion (heating) of the surrounding material during a power transient.
However, it shouid be emphasized thit accompanying the expanains liqusd aro three reactivity effects, all interdependent:

- Mass-importance

- Mean chord leneth (streamine)

- Self-multiplicatior.

The first feedback effect is a result of materlal motion in a neutron importane gradient ( 4.2. , reactivity worth gradient). This effect will, in fisstonine, systems with positive buckling, likely be nomative, of similar or larger magntude than the second efrect and act on the same time scale. The third effect is always amall and negative over a reasmable rance "? liquid state density chanies. However, in the limit of arrays of rial unts win:h are themselves nearly critioal, so]:-rultiplication is the dominant effect. trisr analyses of the second reactivity reodback effect alone and the second and thira $x$ fects in combination have been referenced. The latter are extended in the following section.

A. Magnitude

A qualitative picture (Fig. 1) of the change in the state of criticality of $a$

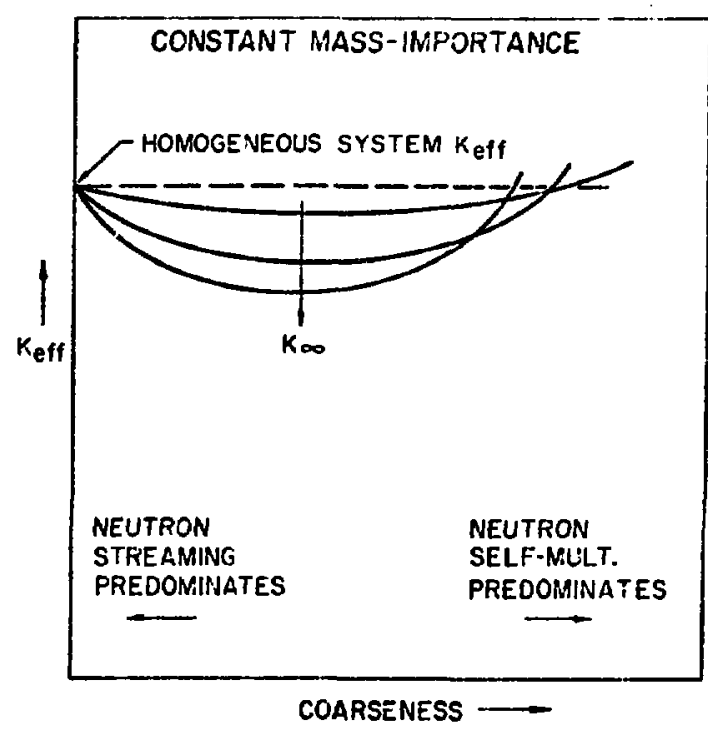

F1g. 1. State of criticality vs system coarseness. 
total nass of fuel within a fixed outer boundary as one changes the system from a homogeneous distribution of fuel to one with increasing coarseness may be drawn based on the two limiting reactivity effects: coarseness very small, Behrens' effect predominates; coarseness very large, self-multiplication as typiried by ORNL experlments predominates. $9,10,11,12$ Changes in the mass-importance are assumed zero in ihis qualitative picture.

Although in a molten fuel situation one would expect to be in the regime where the Eehrens effect predominates over selimultiplication, the calculated net reactivity effect during a power transient is very inodel-dependent since mass-importance thari-es wili be slgniricant.

Since the reactivity effects in questfor :ma be adequidely described by a one ener.y rroup pepresentation, a two-dimenslont? trinspont theory analysis was posslb]e without oxceusive computina costs. In urlep to 150 rate this reactivity feedback, it uas necessary to employ a geom"ry whith suatled mass motion at essen: zily ountant importance.

As r reviousiv reported, 4,7 an adequate $v_{1} \cdot$ :luttunal $: 0.1$ is avallable in the form $\therefore$ the maTRA!l SPFERE computer program. ${ }^{8}$ That this $r y$ role accurately calculates ntu ron streamins for the chosen model has beun vuraiad via Monte Carlo analysis. ${ }^{7}$ This cute emelovs $S_{N}$ transport theory in $r$, spherleal reometry; $r$ beine distance rom the orifin aud being an angle measured from the pole with $0<\theta_{\max } \leq \pi$.

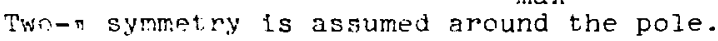
inhis feumitry can best te visualized by inspection of Fif.. 2.

This meometry has the advantage of $r$, e cylninfcal geometry in that mass can be lumped/distributed within an $r$ to $r+$ or shell, essentially eliminatine massimportance effects. In addition it possesses one significant advantage: due to the curvature of the mesh volumes in spherical geometry, neutron streaming paths are

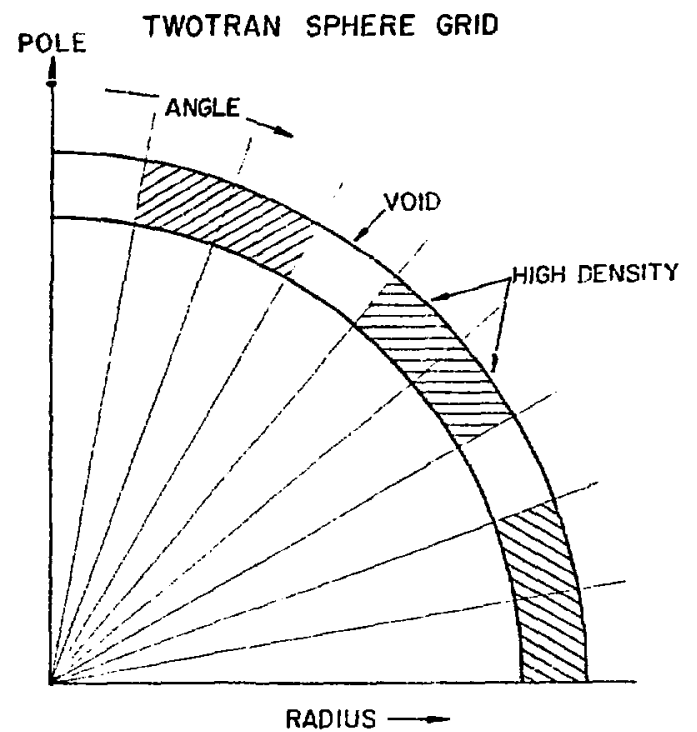

Fis. 2. Example of TWOTRAN SPHERE mesh. Revolution of this plane through 2 radians, about the pole, yields the hemispherical geometry used in the calculations. Note that most volume elements (mesh cells) are somewhat toroldal shaped. Those elements bounding the Pole are frustums of cones. Those elements bounding the origin ( $r=$ o) are spherical sectors.

more well defined and an estimate of an average "bubble" size is more realistic and accurate than for $r, \theta$ cylindrical geometry. From a different viewpoint the spherical geometry is also desirable; it enables comparisons with the theoretical results in Ref. 6.

Prior analyses of the streaming effect with the TWOTRAN SFHERE code wore made for only one system size, $c 53-\mathrm{cm}$ sphere. 4 The infinite medium multiplication ractor for the fuel in that study was $k_{\infty}=1.33$. Those results, together with results for $44-\mathrm{cm}\left(k_{\infty}=1.5\right)$ and $29-\mathrm{cm}\left(k_{\infty}=2.0\right)$ spheres and with vold contents of 10 and 33 vol\% are presented in Figs. 3 through 8.

The only parameter in this work which is subjective is the characterization of the average "bubble" size in the $r, \theta$ spherical geometry. The three coarse meshes $(r \times \theta=10 \times 9 ; 20 \times 18 ; 40 \times 36)$ 


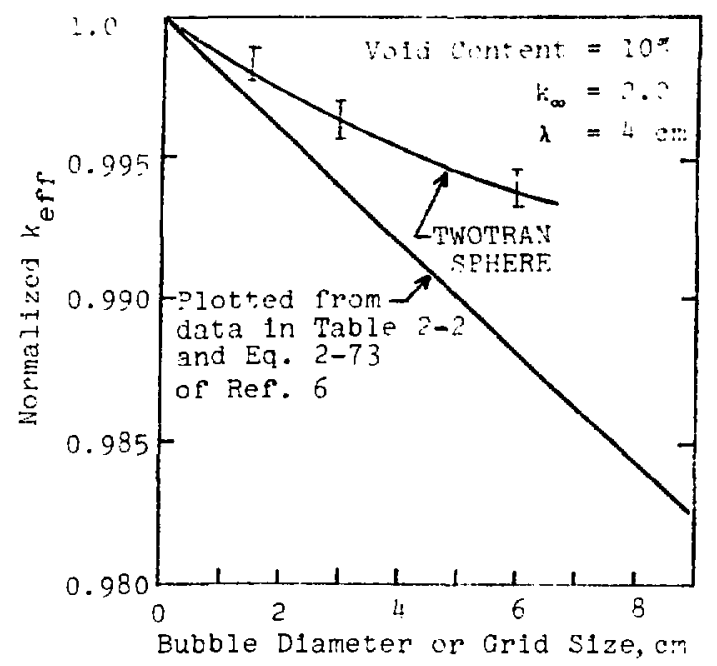

Fig. 3. State of criticality vs syster. coarseness at constant massImportance.

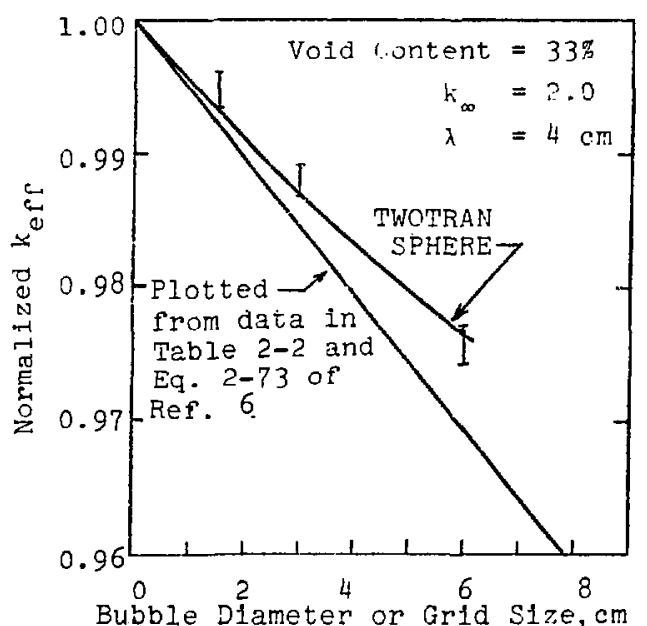

Fig. 4. State of criticaltty vs system coarseness at constant massimportance.

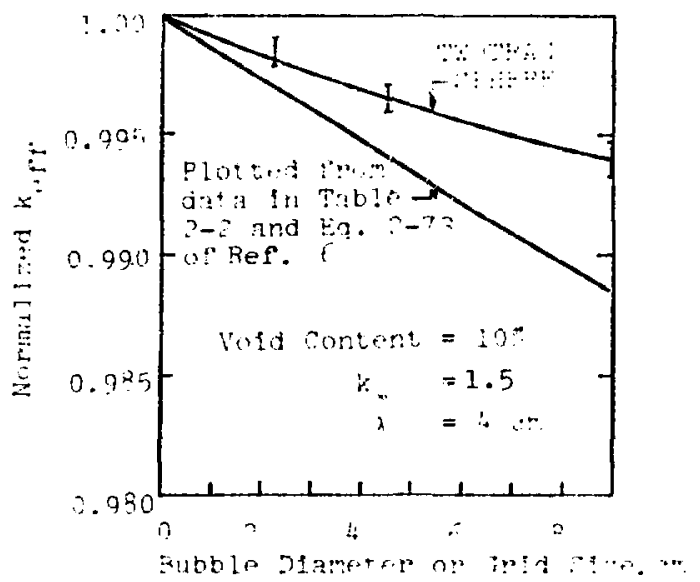

F1g. 5. State of ar1t1:a11ty $\because s$ sys coarseness at constant massImportance.

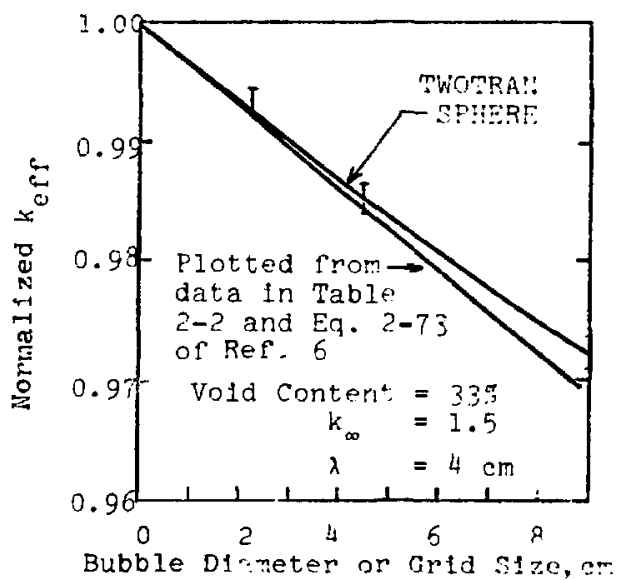

F1g. 6. State of critical1ty vs system coarseness at constant massimportance. 


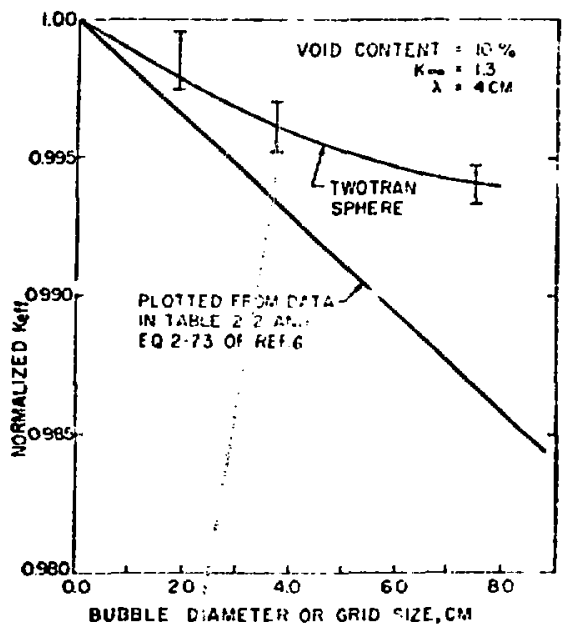

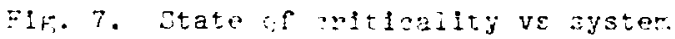
erarsemtoss pt constant lnassimport in:e.

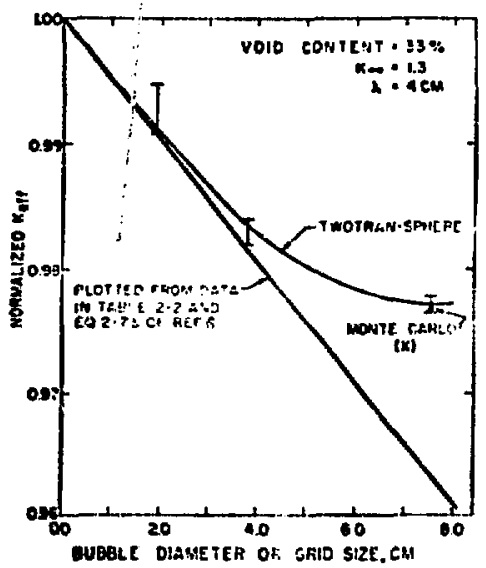

F1;. R. Stare of eritleal1ty us system cuarseness at constant massimportance.

employed in this study correspord to he three data pelnts shown on each rigure. Since each mesh cell in this geometry has is different volume, 1.e., a different average chord sength for neutrons, no attempt was made to calculate an exact average "bubble" size. The error bars represent estimated uncertalntles due to $S_{N}$, rine mesh size and convergence effects. The reactivity shown in these figures is the maximum which would be added to the system
If ali the rolds were :1ilar with the expanding 11gutd. I:, durgar a potulated

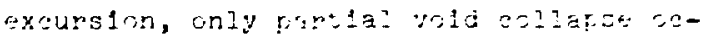
exrred ther chly a frantion of thr eneastzity represented in these plots would be addis :a positive reedisth.

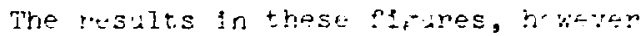

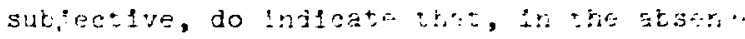

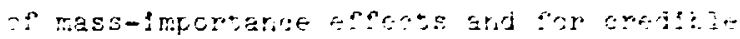

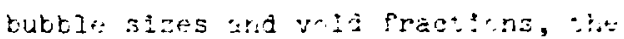

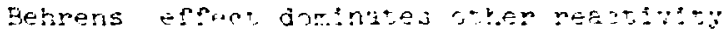

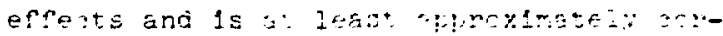
rest as falsulated in Res. f. It is stFnffloant that all ourves mesil:1r: fusm

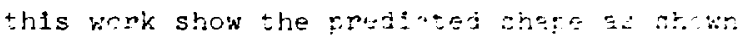
in Fir. i.

In oriar to rejut ibest datepert-

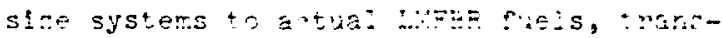

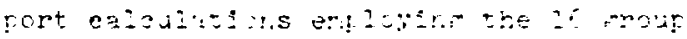
Hansen a:d Bosah oruss-sectzor. set and the

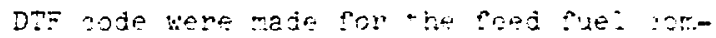

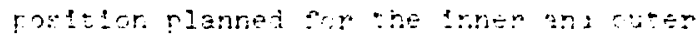

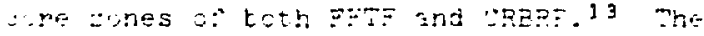

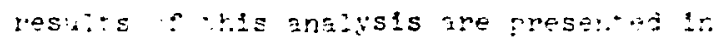

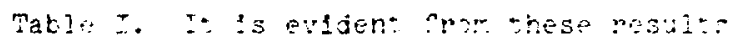

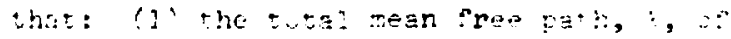

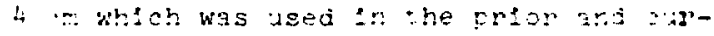

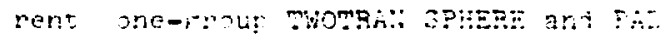
analyses is adequate and (2) the stuites for the 29-cm sphere ane ros: apol1nato for these two fast pesators. Althourt. b. is indepenten: of any $\because y: d$ comtent, numpenized or disirete, the ertteal radius is sironf:y dependent themeon. The ?:ical ract: In Tabie $t$ are base: or 905 dense fue? 10 vole volds?.

TABLE I

FFTF AND CRBRF FEED TUEL CHARACTERTSTICS
Fuel

FFTF Inner

FFTF Outer

CRBRP Inner

CRBRP Outer $k_{\infty}$

1.82

2.10

1.73

2.02
Critical Radius cm

33.3

26.0

35.7

27.5 


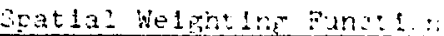

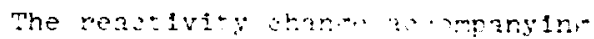

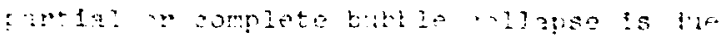

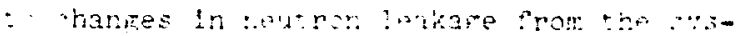

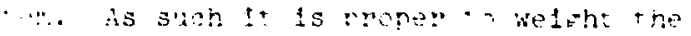

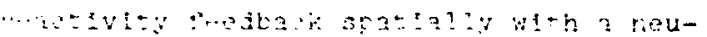

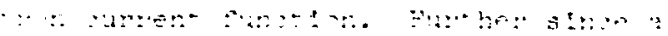

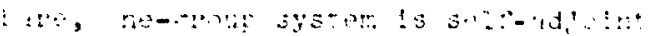

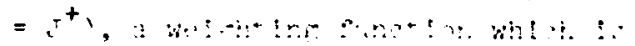

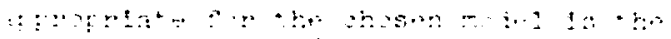

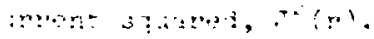

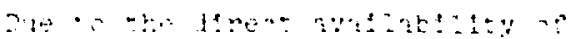

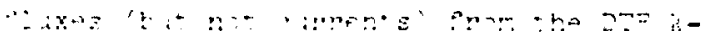

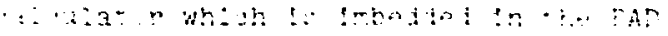

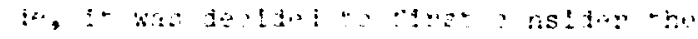

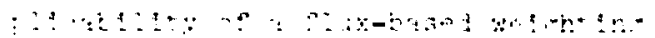

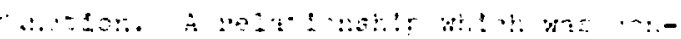

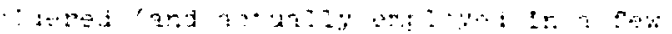

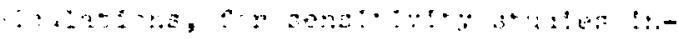

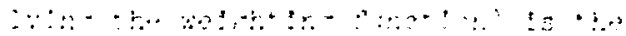
$\therefore: \cdots$

$$
\therefore \quad:^{\prime}=:-:^{\prime}:
$$

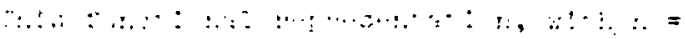

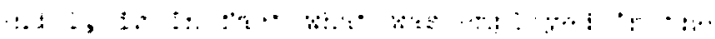

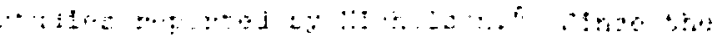

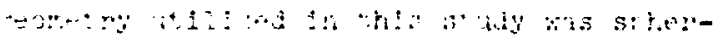

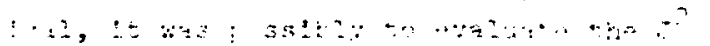

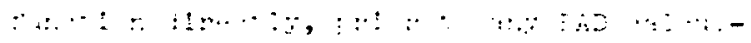

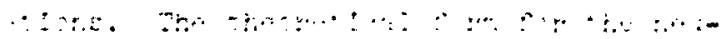

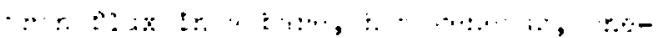

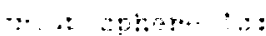

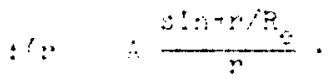

$\because$

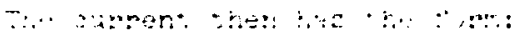

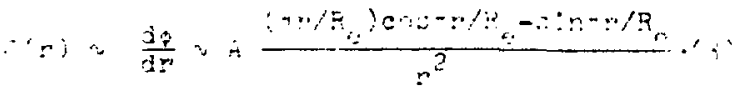

This :unction, nomalized to unit, ampliude, is shown 1r. Fig. 9 for a $53-\mathrm{cm}$ bare sertos and an extropolated atilus, $\mathrm{R}_{e}=$ $\because . \% \mathrm{am}$. The norrix? ized weiphting idno-

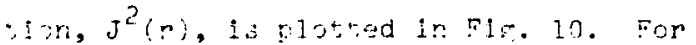

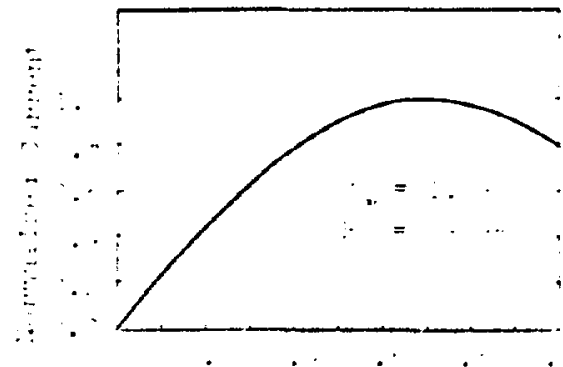

$\therefore: \because: \therefore \because \because \because$

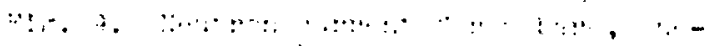
$\because \cdots, \quad \therefore: \cdots, \cdots$.

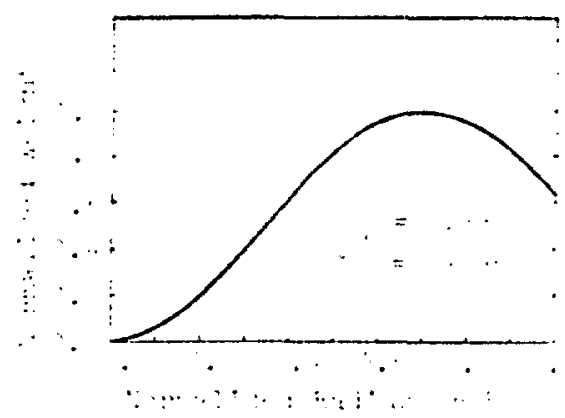

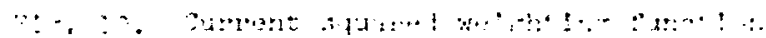

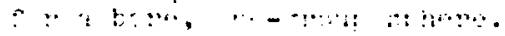

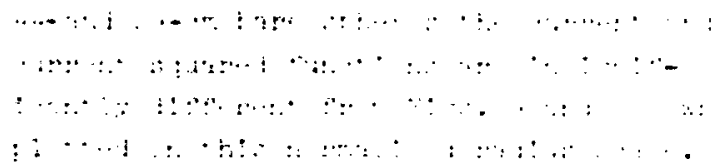

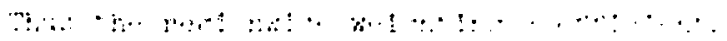

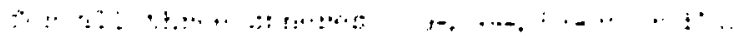

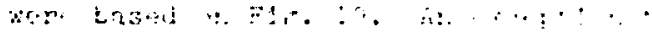

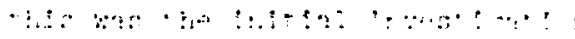
!

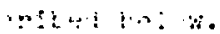

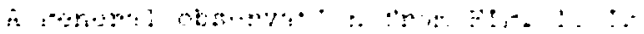

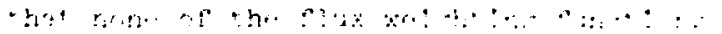

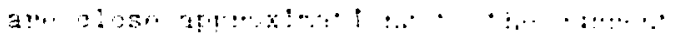

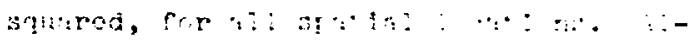

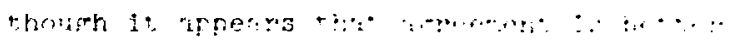

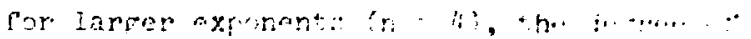

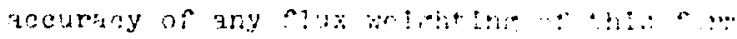

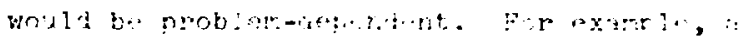

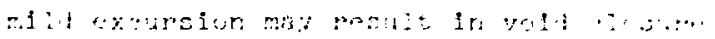

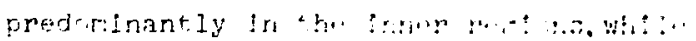

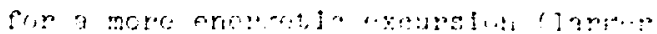




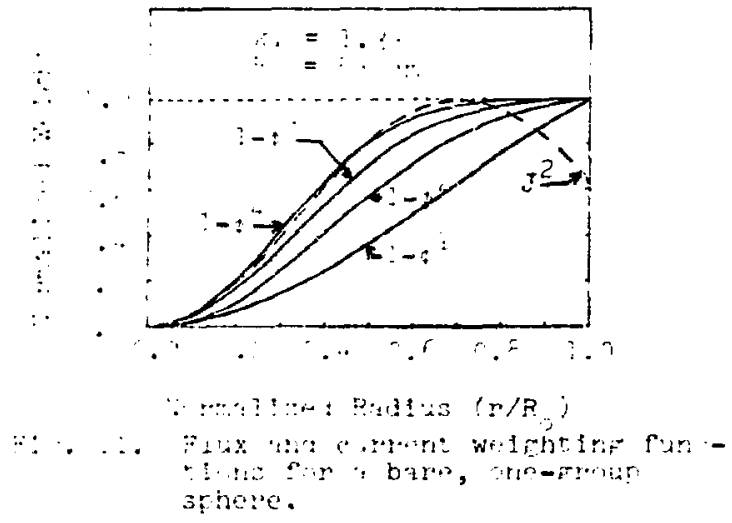

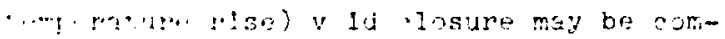

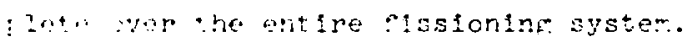

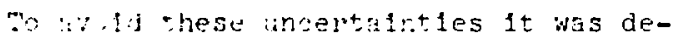
-l.jritr miley the FAD ade to accept

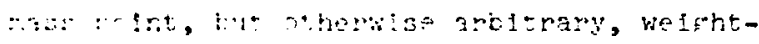

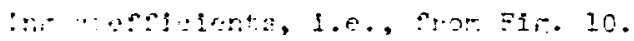

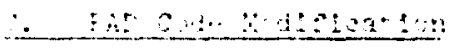

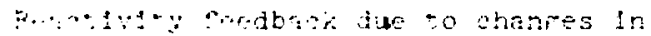

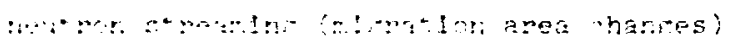

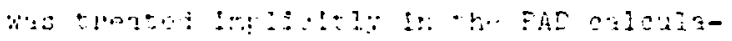

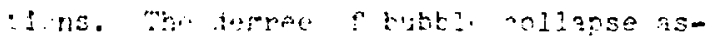

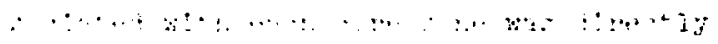

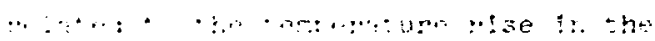

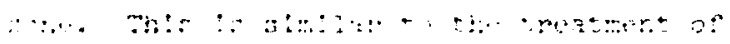

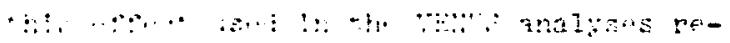

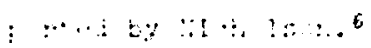

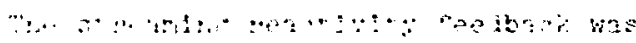

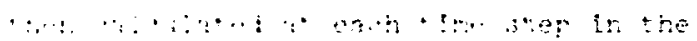

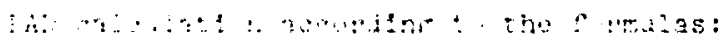

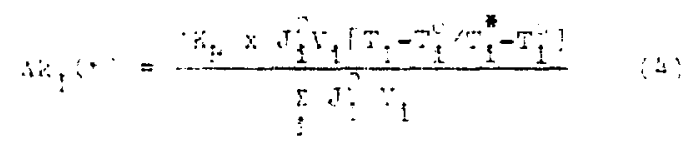

and

$$
\therefore K(t)=\sum_{1} \mathrm{AK}(t)
$$

where

$$
\begin{aligned}
A K_{B}= & \text { Lotal reactivity change asso- } \\
& \text { clated with complete bubble } \\
& \text { eollapse, from Figs. } 3-8 . \\
1= & \text { zone index }
\end{aligned}
$$

$\ddot{i}=$ zone reactivity welghting coefficlert, from elf. 10

$Y_{1}=$ zone volume at 1 ite

$\mathrm{T}_{1}^{+}=$zcre temperat ure at time $t$

$T_{1}^{0}=20 n e$ 1rit: $1=1$ toroperature

$\mathrm{m}_{1}=$ zone temperisure at which the Initial vold content is entire?y fillor by ilgifd fuel expansion. If ir zone vemperature exceeded ${ }^{*}$, then Lir firas held constant at the value corresFonding to $\mathrm{T}^{*}$.

\section{IIT. GEOMETRIC A.D EQUATION OF STATE MODELS}

The rostulated excursion is examined b. the application of two different geomptris and equation of state models. Addi: Lonally the conservitisms and advantages on disadvantages of ecch model are disuscel, rarticulariy in the context of the little collarso reactivity reedback. These malz ar... fientifled by the labels homoroneris and layeled whlch characterize the riel eritiz: distributions. Assoclated with in 3 respective geonetric models are "throsho.j" and "nonthreshold" equation of state treatments, both of which are variaHons af the basio FAD EOS model for the ondensed phase.

The aleulational geometry was mea:mensional, spherical with each rezicr (rass ocint) representing a spherical shil.. The neutronics for determining the state o: criticality, power profile, ind the displacement reactivity feedback was based on a che energy group representation. Initial conditions and other assumptions employed in the PAD calculations are sumarlaed below.

- In1tia? power $=1.0 \mathrm{MW}$

- Initial temperature $=3123 \mathrm{~K}$, this is the PAD mejt temperature for $\mathrm{UO}_{2}$, which is assumed to be liquid.

- InItial density (fully dense) = $8.7 \mathrm{~g} / \mathrm{sm}^{3}$

- Initial state of criticality = prompt critical 


\section{UNCLASSIFIED}

- Prompt neutron 11 fet1me $=67 \mathrm{~ns}$

- No delayed neutrons

- All physical properties $\mathrm{da}^{+} a$ correspona to pure $\mathrm{UO}_{2}$

- System averaged void content $=10$ vol:

- Dopplez constant $=-0.002$

- Total neutron mean free path $=4.0$ $\mathrm{cm}$.

These model specifications are 1dentically those employed in studies reported previously.1,2,3 The $S_{N}$ quadrature and oneEroup cross sections specifled for the PAD anglyses were the same as for the TwOTRAN SPEERE saleulations.

A. PAD zos Model for $\mathrm{jO}_{2}$

Thy hydrodynamic (working) pressure :cn $\mathrm{LO}_{2}$, and for many other materials. in the PAD code, is discretized into condensed phase (solid and liquid) and vapor phase runctions. The condensed state function has the form:

$$
P_{S}=\alpha B\left(T-T_{0}\right)+E / 0\left(0-0_{0}\right)
$$

he

$$
\begin{aligned}
& F_{S}=\text { condensed phase pressure, dynes/ } \\
& x \text { = volime coefficient of expansion, } \\
& 3=\text { tul: molulus, dynes } / \mathrm{cm}^{2} \\
& T=\text { temperature, } K \\
& \dot{\nu}=\text { density, } / \mathrm{cm}^{3} \text {. }
\end{aligned}
$$

in adition to this a vapor phase presistre is allowed, whose temperature dependance is required to follow the satura$\therefore$ : Iin?,

$$
P_{e}=P_{0} e^{-L / R T}
$$

where $L$ is the heat or vaporization, $R$ is the universal gas constant ( 22 cal/g-mole) and $P_{0}$ is a constant determined by requiring that (?) satisfy critical point data. For $\mathrm{UO}_{2}$, the data used in the PAD code are:

$$
\text { - Heat of vaporization }=1866 \mathrm{~J} / \mathrm{g}
$$

- Critical Point: $P=1974$ a: :", $T=7500 \mathrm{~K}$.

With this information Eq.(7) can be s'ived for the 1-atmosphere boll1ne point, resultIng in $\mathrm{T}_{\mathrm{B}}=3650 \mathrm{k}$. Both the heat $a$ vaporlation and bolling point compare riturabl; to recently reported "recommended vilues" (1925 J/R; $3693 \mathrm{~K}$, Ref. 14).

For determinine the vapor ira.tion a perfect sas equation is assumed:

$$
P_{V}=R \circ P
$$

where $P_{V}$ is equated to $P_{e}$ :rosi ${ }^{\cdots}, ?^{\prime}$ :s the mass fraction vaporized, $R$ : 3 i': $: \cdots$, $p$ is the total fuel density iviror + Iquid. and $T$ is temperation. Althrugh the + at $z$ (hydrodynamic) pressure was so: "yd:? :

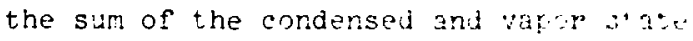
pressures in this study, condensei thase pressures were the mafor disasterlin mohanlsm for all wases presenter in tr: $R:-$ SULTS section.

3. Homoreneous Goometry rode?

In this model the material der.: :y is spatially uniform. The Initial vai son-

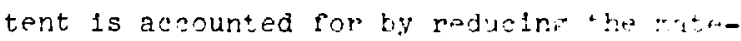
rlal density acuordru to isa isma

$$
\rho=o_{0}(I-F)
$$

$$
\text { where } \begin{aligned}
\rho_{0}= & \text { normal materlal density } \delta t \text { tem- } \\
& \text { perature } T_{0} \\
F= & \text { system inftial void fraction } \\
0= & \text { reduced naterial dansity at tem- } \\
& \text { perature } T_{0} .
\end{aligned}
$$

The 11quid phase equition of $s^{t}, \mathrm{at}, \mathrm{t},(6)$, exhibits 2 "threshold" in this model. Since the second term in this equation 13 negative, positive pressures do not act until the temperature in a zone has reached a value such that

$$
\alpha B\left(T-T_{0}\right)>B / \rho\left(\rho-\rho_{0}\right)
$$

Intial zone temperatures, $T$, are set equal to $\mathrm{T}_{0}$, so that the iirst term, ${ }_{A} \mathrm{~B}\left(\mathrm{~T}-\mathrm{T}_{0}\right)$, is 


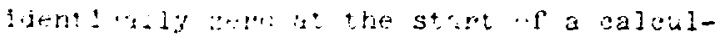

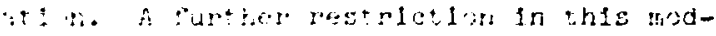

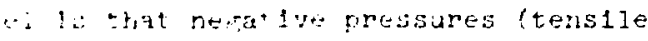

strengths) are not ailowed, 1.e., if the

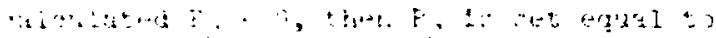
$\because \cdots+\cdots$

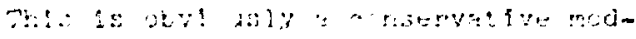

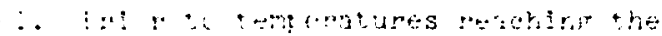

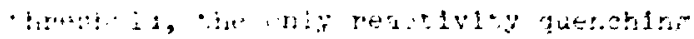

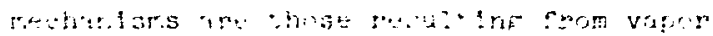

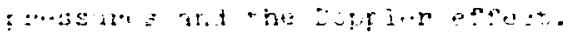

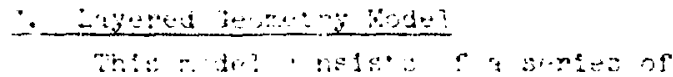

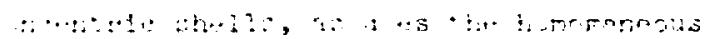
d: : ! :

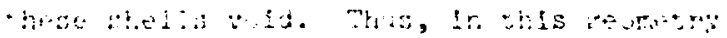

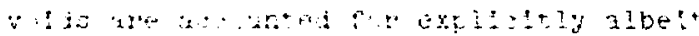

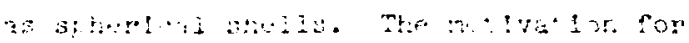

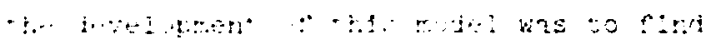

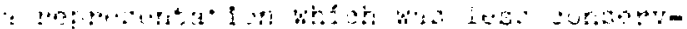

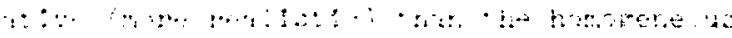

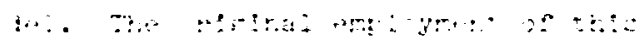
$\because$.

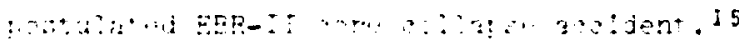

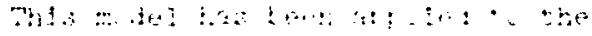

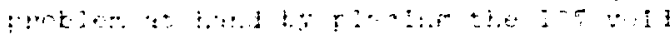

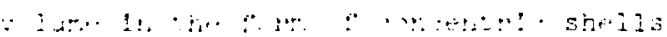

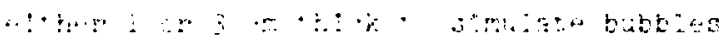
" ' 1nj:

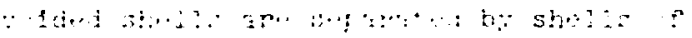

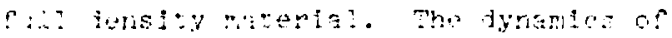
the tas ride allow motton b th inwnad and

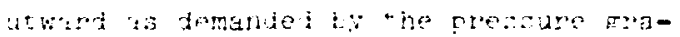

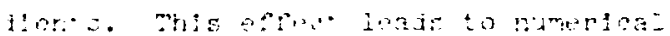

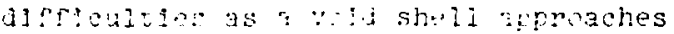

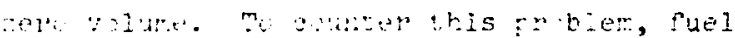

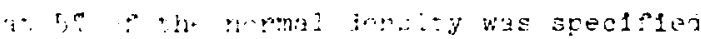

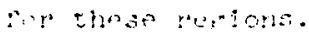

The condersed phas equation of stite, (6), For the fully donse zones has $p=2$ and $T=T_{0} I^{t}$ the start of the PAD calculgtions. Therefure for these zones there is no "threshold"; prossures rise as sonn is temperatures Irerease. Expansions follow which lead directly to material motion feedback as calculated by explici: transport (DTF) analysis.

\section{Model Conservatisms}

Both of the models employed have offferert advantapes, clsadvantaces, and conservat $1 \mathrm{sms}$. Althcurn a itguld ocntafring bittles is no: homofereaus, communisetsor: piths from renter to edze would exist, aisonlre antsmission of pressure wates. The yelogty of the proscure rayes would be :eruced rejative to a tily jense syster le.;., ine gudua nesturi. The degree on reriation is derencert $3 n$ the buttle size,

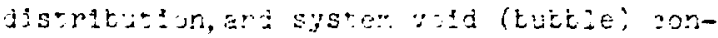

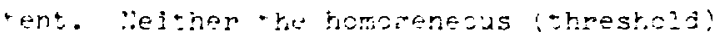
rodel ricr the layered noje: l.mets trat rrossure waye pronafotidr; for thas rossor. tat are zorsorvitive.

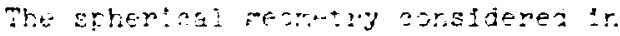

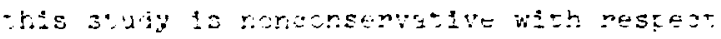

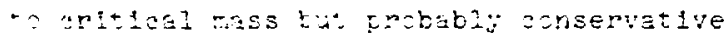

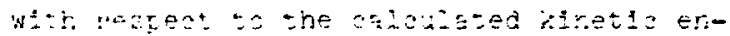

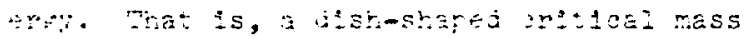

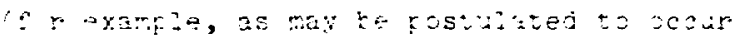

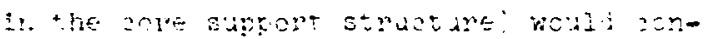
- In wore mass thar a anitizal sphere of tho sare fissize raver1a:. Huwever, the

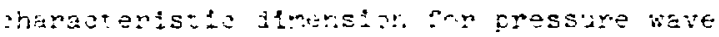

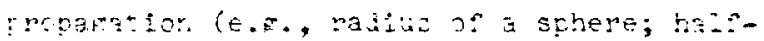
- hiliness o: a siot! is zirker for ine

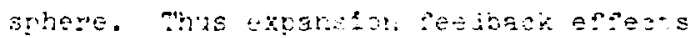
w12 be folt sooner 1r nonsphewsal -ecr$=r \cdot y$.

Erior sludis rave injleated the re-

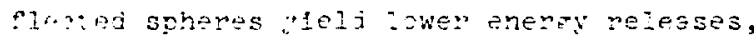
stressures, and temrerasures than bare spheres.1"? mis is mos: probat 1 y jue id the smaller oritiasl mass for the sarie ive] material, sn the rellected case. Adis:ionaly, since the streming reartivity effect is dincetiy related to system leak$2 F e$, it follows that for reflected systems any bubble collarse reactivity feecback calculated for a bare sphere is conservative when applied to the reflected sphere. an LMPBR core meltdown were to occur and, further, a molten fuel recrlticality were postulated, then there would necessarliy be reflection over $\approx$ one-ilals of the surface of the contalned molten fuel. Thus from 
buth expansion and streaming reactivity :eedback considerations any realistic geometry is conservative relative to the idealized, bare geonetries analyzed herein.

The threshold model has been widely applied to postulated molten fuel racriticality studies because it is believed to be conservative and allow the calculation of bounding values (energy releases, temperatures, pressures, etc.). Certainly if one couples an additive, posit!re reactivity feedback (to model posisible streaming effects) to a threshold EOS model, then there is a very high degree of consenvatism in the analysis, at least from these considerations.

The layered model was developed to provide a description somewhat less conservative than the threshold model but which still allowed for inhomogeneities of an arbitrary nature to be modeled. Reartivity changes caused by expanston of the fuel into the voided shells are calculated correctly (except that the onedimensional model does not inherently account for the bubble collapse effect, which was then handled separateiy), and the outermost surface is allowed to expand. But, as noted above, a pressure wave generatad in the center is not propagated outward in a realistic manner. AIl factors considered, this model is judged to be conservative and, for the case at hand, a better approximation to the hypothetical model than the homogeneous (threshold) model.

\section{RESULTS}

Parameter variations in the present study included reactivity insertion rate, geometric and equation of state models and streaming reactivity feedback (magnitude and spatial weighting). The void fraction and Doppler coefflcient were held constant at 0.10 and -0.002 , respect1vely. Studies varying these latter two parameters, but without consideration of streaming reactivity effects, ha\%e been reportied. ${ }^{3}$

Power, fission energy, and kinetic energy histories from a PAD calculation for one of the cases are shown in Fig. 12. The corresponding net ard individual rezctivity traces are glven in Fig. 13. These results are qualitatively representative of $I^{\text {* }}$ cases studied, including the above referenced work on multizone systems (radially varying void fractions). This consistency Is due to a common, dominant material motion mechanism, namely, liquid state pressures.

Since the system temperature rise follows the fission energy deposition history, it is apparent from Fig. 12 that temperatures begin to rise substantially at about $1.8 \mathrm{~ms}$ and maximum values are reached by $2.4 \mathrm{~ms}$. This temperature-time dependense explains the Doppler ard streaming reactivity feedback traces on Fig. 13. For this particular case it is noteworthy that although the streaming reactivity feedback model resulted in the insertion of almost twice the reactivity removed by Doppler feedback, this did not aggravate the excursion greatly. Material motion feedback,

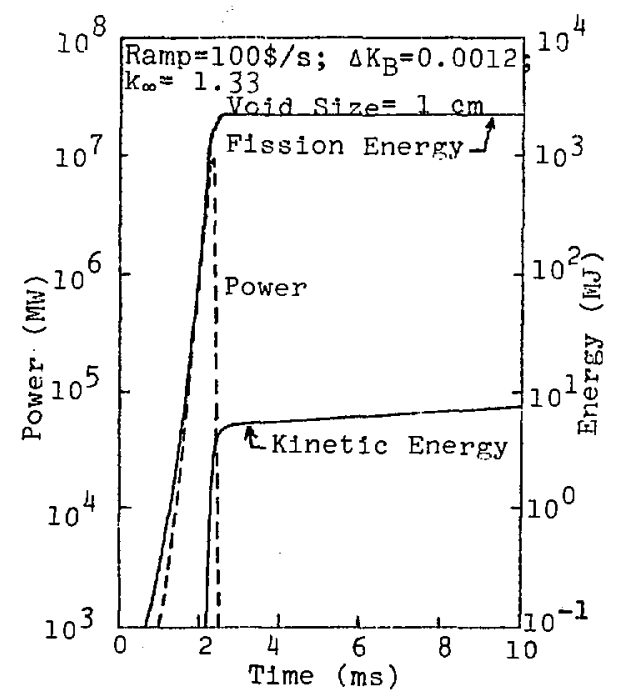

rig. 12. Power and energy historles for a typical case. 


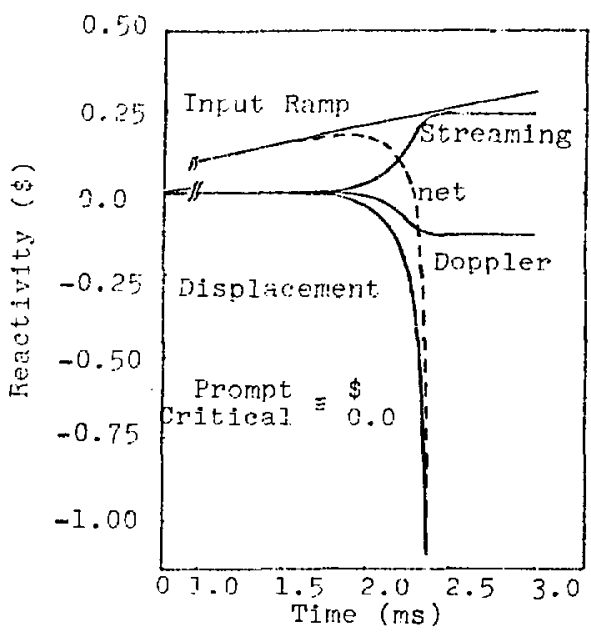

Fig. 13. Input, feedback and net reactivity histories.

which occurred on the same time scale as the former, was dominant.

The higl solid state pressures which precipitate the material motion also provide the explanatjon for the initial, steep rise in the kinetic energy trace. After the power burst is complete ( $22.4 \mathrm{~ms}$ ), expansion of the dense regions into the volded refions and expansion at the outer boundary quickly relieve the liquid phase pressures. The subsequent slow rise in the kinetic energy results from the generation of fuel vapor pressures.

The paranetric survey of cases studied is presented in Tables II, III and IV for critical spheres of $29.0,44.0$ and $53.0 \mathrm{~cm}$ respectively. There are several points to be noted from these tables.

- Energy releases (fission and xinet1c) are stiongly dependent on both the degree of model heterogeniety (i.e., homogeneous; $1.0 \mathrm{~cm}$ shells; $3.0 \mathrm{~cm}$ shelis) and the magnitude of the streaming reactivity feedback.

- Energy releases Increase monotonically with the system critical mass.

- Results for homogeneous model calculations without streaming feedback are similar to those results which employed the layered model with a best estimate $\Delta K_{B}$.

- For very reactive fuel $\left(k_{\infty} \sim 2.6\right)$, reactivity insertion rates in excess of $\$ 1000 / \mathrm{s}$ would be necessary for a destructive excursion.

- The streaming reactivity weighting function plays a relatively unimportant role, at least when employed
TABDEE TI

PAI RESLLTS FOR $2 \mathrm{~g}=\mathrm{CK}$ SPHERE

$K_{m}=2.0$ Vold Fraztion $\approx 0.20$

\begin{tabular}{|c|c|c|c|c|c|c|c|}
\hline $\begin{array}{c}\text { Yold s1ze } \\
\mathrm{cm}\end{array}$ & $\Delta k_{B}$ & $\begin{array}{c}\text { P1ssion Energy } \\
\text { MU }\end{array}$ & $\begin{array}{c}\text { Kanetie Energy } \\
\end{array}$ & $\begin{array}{l}\text { Core Average } \\
\text { Temperature, } \mathrm{X}\end{array}$ & $\begin{array}{l}\text { Gore Averaze } \\
\text { Pressure, atm }\end{array}$ & Max. Pnwer & Kax: AIpha \\
\hline \multicolumn{8}{|c|}{$50.3 / \mathrm{s}$} \\
\hline i. 0 & .0025 & 16 & 20 & 3360 & $\approx 0$ & $3.2+4$ & $2.2+3$ \\
\hline \multicolumn{8}{|c|}{$100 \$ / \mathrm{s}$} \\
\hline H & 0.0 & 300 & 0.4 & 3820 & 3.8 & $1 .: 6$ & $6.5+3$ \\
\hline 1.0 & 0.0 & 70 & 20 & 3280 & 70 & $2.3+5$ & $5.5+3$ \\
\hline 1.0 & $.30=5$ & 220 & $\approx 0$ & 3380 & $\approx 0$ & $2.5+5$ & $5.7+3$ \\
\hline 1.0 & .0050 & 320 & 1.0 & 3800 & 5.0 & $1.1+6$ & $6.0+3$ \\
\hline \multicolumn{8}{|c|}{3 no $1 /$ s } \\
\hline i.0 & .0025 & 330 & 1.0 & 3810 & 4.5 & $1.5+6$ & $1.3+4$ \\
\hline \multicolumn{8}{|c|}{$1000 \div / 0$} \\
\hline 2.0 & .0025 & 566 & 3.1 & 4230 & 11.2 & $7.3+6$ & $2.7+4$ \\
\hline
\end{tabular}


TARLE III

PAn REsLLTS FOAl 11-CI GPHERE

$x_{-}-1.30 \quad v i d a$ froction $\approx 0.10$

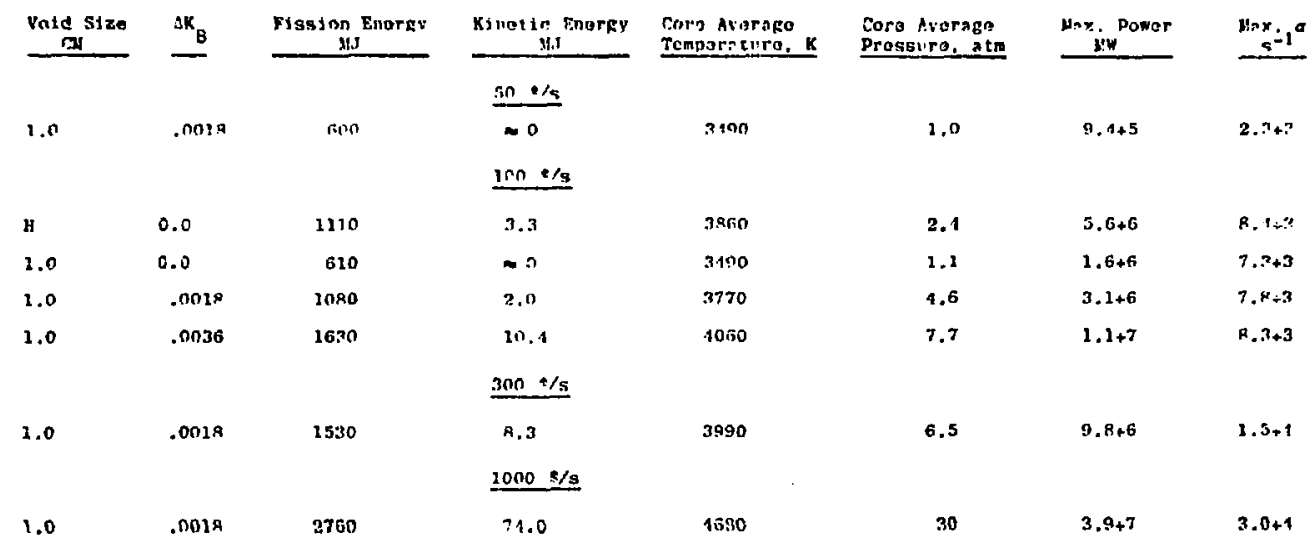

TABLE IV

PAD RESUTTS FOR S? CN SPLE.FE

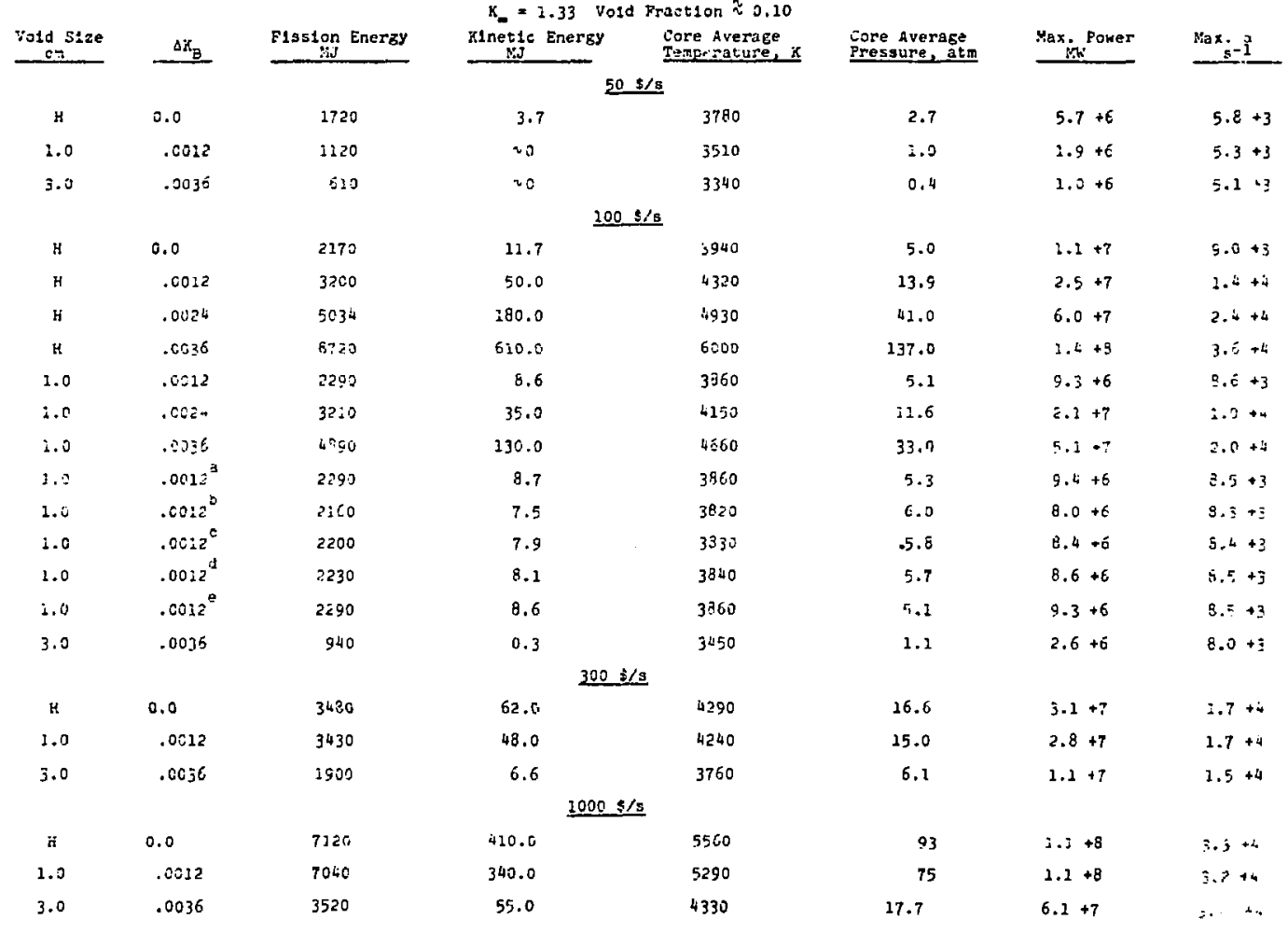

Plux welght: nx exponent $\left(W-1-+^{n}\right) ; \quad a(n=0) ; \quad b(n=1) ; \quad c(n=2) ; \quad d(n=3) ; \quad$ e(n-4) 
in confunction with the iayered mode 1 .

Due to the diversity of the parameter varlations present in these iables, only a part thereof is sultabie for graphical presentation. For layered model cases with 1.0-cm-thick volded shelis and the best estimate $\Delta K_{B}$, flssion and kinetic energy releases are shown in Figs. 14 and 15 , respectively.

\section{CONCLUSIONS}

Two highly idealized models of a hypothetical molten fuel recriticality accident have been developed and applied, via the PAD code, to determine energy releases and other significant parameters which characterize the postulated excursions. Within the framework of the stated models and assumptions it is concluded that:

- A negliglble explosive potential exists for these hypothetical situations unless there exist mechanisms (with sufficient probability) for inserting reactivity at extremely high rates.

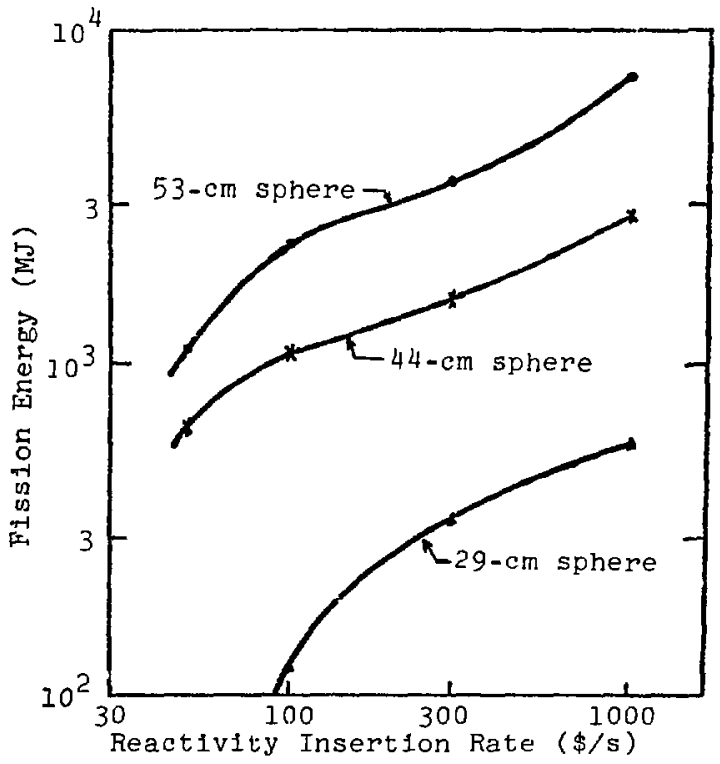

Fig. 14. Fission energy deposition for layered geometry models.

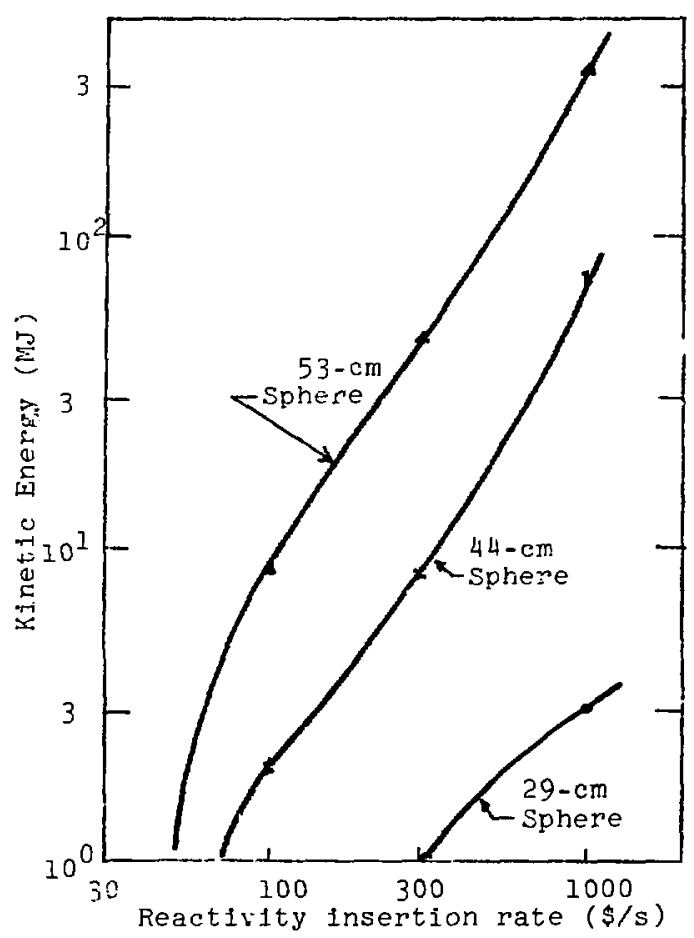

Fig. 15. Kinetic energy (at $V / V=8$ ) for layered geometry model $\$$.

An attempt has been made to examine the models and assumptions employed in this analysis relative to the degree of conservat $1 \mathrm{sm} /$ nonconservatism in each. It is believed that the coupling of a streaming reactivity feedback formalism to a homogeneous (threshold) geometric and equation of state model is compounding conservatism to a high degree. The layered model, while st1l1 consldered quite conservative when the streaming reactivity feedback is added thereto, is belleved to be a more reailstic model for the postulated scenario.

\section{REFERENCES}

1. William R. Stratton, Leon B. Engle, and Donald M. Peterson, "Energy Release from Meltdown Accidents," Trans. Am. Nucl. Soc. 17, 362 (1973).

2. Thomas P. Melaughlin, Donald M. Peterson, and William R. Stratton, "Energy Release Irom Molten-Fuel Recriticality Aceldents," Trans. Am. Nucl. Soc. 18, $198(1974)$. 
3. Thumas F. Motaughiln, Donald M. Peterson, and Willam R. Stratton, Pajarito Reactor Safery Program unpublished process report, Sentember 1974.

4. Thomas P. Melauknlin, Donald M. Peterson and William R. Stratton, Pajarito Reactor Safety Program unpublished progress report, November 1974.

5. D. J. Behrens, "The Effect of Holes in a Reacting, Material on the Passage of Neutrons," Proc. Phys. Soc. Lonaion, Sea. A, 62, 607-616 (1949).

6. R. B. Nicholson, "Design Bases Accident Studies," ERDA Chicago Operations office report Co0-2266-3 (June 22, 1974).

7. Thomas P. Mclaughlin and G. David Turner, "Reactivity Changes due to Bubble Growth on Collapse in Molten Fuel Systems," Trans. Ari. Nucl. Soc. 21, 281 (1975).

8. Kaye D. Lathrop and Forrest W. Brinkley, "TWOTRAN SPHERE: A FORTRAN Program to Solve the Multigrolp Transport Equation in Two-Dimensional Spherical Geometry," Los Alamos Scientific Laboratory report LA-4567 (November 1970 ).

9. Joseph T. Thomas, "Critical Three-D1mensional Arrays of U(93.2)-Metal Cylinders," Nucl. Sei. Eng. 52, 350-359 (1973).

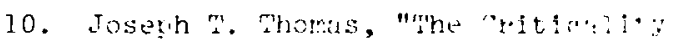

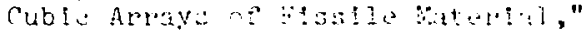

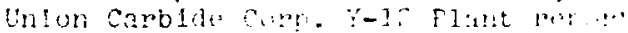
$\mathrm{Y}-\mathrm{CDC}-10(\mathrm{l} \times \mathrm{V} .3, \mathrm{3} 971)$.

11. Joseph T. Thomas, "Uransur Mrtal crptlcality, Monte Car. o Caleulations and Nuclear criticality Safety," irtion Carbide Corp. Y-12 Plant report Y-CDC-? (Oct. 5, 1970).

12. Joseph T. Thomas, "Generie Arriy Cr:"lcality, an Analytic Representation of Reflected Arrays of Fissile Unit: " Union Carbide Cort. Y-12 flant renort $Y-C D C-13$ (Aug. 1, 1973).

13. Clinch River Breeder Reactor Propict, PSAR, 4, Table 4.3-30, (2975).

14. Rajendra Kumar, L. Ba'ier, Jr., and M. G. Chasanov, "Ex-Vessel Consideration in Postaceident Heat Removal," Argonne Natlonal Laboratory report ANL/RAS 74-29 (October 1975).

15. Wllilam R. Stration, T. H. Calvin,and Roger B. Lazarus, "Analysis of Prompt Excursions in Simple Systeris and Idealized Fast Reactor's," Second International conference on the Peaceful Uses of Atomic Enerpy, 1958, volume 12, page 196. 